\title{
Correction to: The influence of cross-sectional channel geometry on rheology and flux estimates for active lava flows
}

\author{
Einat Lev ${ }^{1} \cdot$ Mike R. James ${ }^{2}$
}

Published online: 4 February 2020

(C) International Association of Volcanology \& Chemistry of the Earth's Interior 2020

\section{Correction to: Bull Volcanol (2014) 76:829}

https://doi.org/10.1007/s00445-014-0829-3

The original version of this article unfortunately contained a mistake. The text accompanying Eq. 3 in the published paper should be corrected.

Currently:

$\gamma=1-\frac{384}{\pi^{5}} \sum_{n=1,3,5 \ldots}^{\infty} \frac{1}{n^{5}} \tanh \frac{2 a n \pi}{4 \mathrm{~h}}$

Should be:

$\gamma=1-\frac{384}{\pi^{5}} \sum_{n=1,3,5 \ldots}^{\infty} \frac{1}{n^{5}} \frac{h}{2 a} \tanh \frac{2 a n \pi}{4 \mathrm{~h}}$

The online version of the original article can be found at https://doi.org/ 10.1007/s00445-014-0829-3

Einat Lev

einatlev@1deo.columbia.edu

1 Lamont-Doherty Earth Observatory, Columbia University, New York, NY, USA

2 Lancaster Environment Centre, Lancaster University, Lancaster, UK 